\title{
Long polar fimbriae participates in the induction of neutrophils transepithelial migration across intestinal cells infected with enterohemorrhagic E. coli O157:H7
}

\author{
Alejandra F. Vergara ${ }^{1}$, Roberto M. Vidal ${ }^{2}$, Alfredo G. Torres ${ }^{3 *}$ and Mauricio J. Farfan ${ }^{1 *}$ \\ ${ }^{1}$ Departamento de Pediatría, Centro de Estudios Moleculares, Hospital Dr. Luis Calvo Mackenna, Universidad de Chile, Santiago, Chile \\ 2 Programa de Microbiología, Facultad de Medicina, Instituto de Ciencias Biomédicas, Universidad de Chile, Santiago, Chile \\ ${ }^{3}$ Department of Microbiology and Immunology, Department of Pathology, University of Texas Medical Branch, Galveston, TX, USA
}

\author{
Edited by: \\ Nora Lía Padola, Universidad \\ Nacional del Centro de la Provincia \\ de Buenos Aires, Argentina \\ Reviewed by: \\ Fernando Navarro-Garcia, Center for \\ Research and Advanced Studies, \\ Mexico \\ Marina Sandra Palermo, National \\ Council of Scientific and Technical \\ Research-CONICET, Argentina \\ Roxane Piazza, Butantan Institute, \\ Brazil

\section{*Correspondence:} \\ Alfredo G. Torres, Department of \\ Microbiology and Immunology, \\ University of Texas Medical Branch, \\ 301 University Blvd., Galveston, TX, \\ USA \\ e-mail: altorres@utmb.edu; \\ Mauricio J. Farfan, Departamento de \\ Pediatría, Centro de Estudios \\ Moleculares, Hospital Dr. Luis Calvo \\ Mackenna, Universidad de Chile, \\ Antonio Varas 360, Providencia, \\ Santiago, Chile \\ e-mail:mfarfan@med.uchile.cl
}

Enterohemorrhagic Escherichia coli (EHEC) strains are causative agents of diarrhea and hemorrhagic colitis, both diseases associated with intestinal inflammation and cell damage. Several studies have correlated EHEC virulence factors to high levels of intestinal pro-inflammatory cytokines and we have previously described that the Long polar fimbriae (Lpf) is involved in the secretion of interleukin-8 (IL-8) and up-regulation of genes belonging to the NF-kB pathway using non-polarized epithelial intestinal T84 cells. In the current study, we evaluated the two EHEC 0157 Lpf fimbriae (Lpf1 and Lpf2) for their ability to induce intestinal secretion of IL-8 and the activation of IL8, CCL20, and ICAM1 genes on polarized T84 cells. We also determined the participation of Lpf1 and Lpf2 in transepithelial migration of polymorphonuclear neutrophils (PMNs). Polarized T84 cells infected with EHEC revealed that both, Lpf1 and Lpf2, were required for the secretion of IL-8 and the induction of IL8,CCL20, and ICAM1 genes. Both fimbriae also played a role in the migration of PMNs trough the intestinal cells monolayer. Overall, the present work further demonstrated that the fimbriae Lpf1 and Lpf2 are important bacterial virulence factors that might be involved in the inflammatory responses associated with EHEC infections.

Keywords: enterohemorrhagic E. coli, shiga toxin E. coli, long polar fimbriae, inflammation, PMN migration

\section{INTRODUCTION}

Enterohemorrhagic Escherichia coli (EHEC) is recognized as a food-borne human pathogen and an important etiological agent of bloody diarrhea in developing/industrialized countries and, in some instances, causative agent of hemolytic uremic syndrome (HUS) (Pennington, 2010). In humans, EHEC infection are characterized by the adherence of the bacteria to intestinal cells and the induction of an inflammatory process characterized by activation of the MAPK, AP-1, and NF-KB intracellular signaling cascades, leading to secretion of pro-inflammatory markers, including interleukin 8 (IL-8) (Dahan et al., 2002; Miyamoto et al., 2006).

Several virulence factors have been associated with the EHECmediated inflammatory process, including LPS, flagellin, and HCP pili (Farfan and Torres, 2012). Recently, we described that the Long polar fimbriae (Lpf) are one of the EHEC adherence factors mediating intestinal inflammation (Farfan et al., 2013). In EHEC O157:H7, two Lpf fimbriae has been described, Lpf1 and Lpf2 (Torres et al., 2002, 2004) and we found that the amount of IL-8 in the supernatant of cells infected by an isogenic EHEC lpfA1 lpfA2 double mutant was significantly less as compared to cells infected with the wild type EHEC strain 86-24. Gene-expression analyses revealed that IL1A (Interleukin1A), TNF (Tumor necrosis factor), SELE (E-selectin), ICAM1 (Intercellular adhesion molecule-1), IL8 (Interleukin 8), CCL20 (Chemokine ligand 20), among other genes, were downregulated in cells infected with the lpfA1 lpfA2 double mutant (Farfan et al., 2013).

During the inflammatory response at the intestinal mucosa, neutrophils are key cellular components contributing directly in the resolution of the infection caused by enteric pathogens. The polymorphonuclear neutrophils (PMNs) migrate across the epithelial layer to reach the lumen and their recruitment is tightly controlled by chemokines and surface-exposed proteins produced by intestinal epithelial cells (Szabady and McCormick, 2013). IL-8, CCL20, and ICAM-1 are key proteins responsible for the chemoattraction and PMNs recruitment to the infection site (Coburn et al., 2005). Because the contribution of each Lpf fimbriae to the EHEC-induced inflammation of intestinal cells has not been evaluated, in this study we sought to evaluate the individual contribution of Lpf1 and Lpf2 in the induction of IL-8 secretion and also determine their involvement in the 
transepithelial migration of PMNs during EHEC infection using polarized intestinal cells.

\section{MATERIALS AND METHODS \\ BACTERIAL STRAINS AND CULTURE CONDITIONS}

EHEC O157:H7 strain 86-24 and its isogenic mutant strains CDV468 (lpfA1 mutant) (Torres et al., 2002), AGT201(lpfA2 mutant) (Torres et al., 2004), and AGT210 (lpfA1 lpfA2 double mutant) (Torres et al., 2004) were used in this study. All EHEC strains were grown overnight in Dulbecco's modified Eagle's medium (DMEM)/0.5\% glucose (DMEM-HG) or Luria-Bertani (LB) broth with the addition of streptomycin $(100 \mu \mathrm{g} / \mathrm{ml})$, chloramphenicol $(30 \mu \mathrm{g} / \mathrm{ml})$ and tetracycline $(12.5 \mu \mathrm{g} / \mathrm{ml})$, when appropriate.

\section{T84 CELL CULTURE CONDITIONS}

Human colonic T84 intestinal epithelial cells (ATCC CCL-248) were routinely maintained in DMEM-F12 media, supplemented with $10 \%$ fetal bovine serum (FBS), penicillin $(10 \mathrm{U} / \mathrm{ml})$ and streptomycin $(10 \mu \mathrm{g} / \mathrm{ml})$, at $37^{\circ} \mathrm{C}$ under $5 \% \mathrm{CO}_{2}$.

\section{T84 POLARIZED ADHERENCE ASSAYS}

Adherence assay was performed with T84 cells in 12-well polycarbonate transwell filters with $0.4 \mu \mathrm{m}$ pore (Corning) as described (Harrington et al., 2005). Medium was aspirated from the apical compartment and $\sim 2 \times 10^{6}$ bacteria were added to the monolayer. Plates were incubated at $37^{\circ} \mathrm{C}$ in $5 \% \mathrm{CO}_{2}$ for $3 \mathrm{~h}$ and then washed $5 \times$ with PBS. Cells were lysed with a solution of $1 \%$ (vol/vol) Triton X-100 and the serial dilutions of the lysates were seeded on LB agar plates supplemented with streptomycin. The number of adherent bacteria was determined by enumerating the resulting colonies. For serum blocking assay, a solution containing $\sim 2 \times 10^{6}$ of bacteria strain 86-24 was incubated with serum raised against the Lpf1 or pre-bleed serum for $1 \mathrm{~h}$ at room temperature prior addition to the cell monolayer.

\section{Lpf FIMBRIAE EXTRACTION}

We obtained an enriched-fraction of fimbriae filaments as described (Izquierdo et al., 2014). Briefly, EHEC strains were grown in DMEM/HG at $37^{\circ} \mathrm{C}$ with shaking until an optical density at $600 \mathrm{~nm}\left(\mathrm{OD}_{600}\right)$ of 1.0 was reached. Cells were harvested by centrifugation at $6000 \times \mathrm{g}$, re-suspended in $1.0 \mathrm{ml}$ of a solution containing $0.5 \mathrm{mM}$ Tris and $75 \mathrm{mM} \mathrm{NaCl}$, and heated to $65^{\circ} \mathrm{C}$ for $30 \mathrm{~min}$. Later, cells were pelleted by centrifugation at $6000 \times \mathrm{g}$ for $10 \mathrm{~min}$ and supernatants were recovered and centrifuged at $21,000 \times \mathrm{g}$ for $30 \mathrm{~min}$ to remove the remaining debris. Fimbriae extracts were dialyzed in PBS using Microcon ${ }^{\circledR}$ filter devices. Total protein was quantified and stored at $-20^{\circ} \mathrm{C}$ for further analysis. To evaluate the induction of secretion of IL- 8 of fimbrial extract in polarized T84 cells, each well was incubated with $200 \mu \mathrm{g}$ of total protein.

\section{IL-8 SECRETION}

Culture medium from triplicate wells of polarized T84 cell monolayers infected with EHEC obtained at $3 \mathrm{~h}$ after infection were evaluated in triplicate by ELISA for IL- 8 as previously described (Harrington et al., 2005).

\section{REAL-TIME PCR}

Total RNA was obtained from polarized T84 cells infected for $3 \mathrm{~h}$ with EHEC strain 86-24 or its isogenic lpf mutants using Total RNA I (Omega Biotech) and treated with RNase-free DNase I (Omega Biotech). Two micrograms of RNA was reversetranscribed into single-stranded by using kit AffinityScript ${ }^{\mathrm{TM}}$ qPCR cDNA (Stratagene). The synthesized cDNA was used to quantify the expression the IL8,CCL20, and ICAM1 genes using the following primers: IL\& F (ACT TCT CCA CAA CCC TCT GC), R (TCT GCA GCT CTG TGT GAA GG) (Sawa et al., 2008); CCL20 F (TTT GCG CAC ACA GAC AAC TT), R (GCT GCT TTG ATG TCA GTG CT) (Gobert et al., 2007); ICAM1 F (CCC ATT ATG ACT GCG GCT GCT), R (AGG CCA CCC CAG AGG ACA AC) (Sawa et al., 2008); GAPDH F (TCC ACC ACC CTG TTG CTG TA), R (ACC ACA GTC CAT GCC ATC AC) (Paulukat et al., 2001). The mRNA expression levels were normalized to those of the human housekeeping gene glyceraldehyde 3-phosphate dehydrogenase $(G A P D H)$. Changes in cycle threshold $(\triangle \mathrm{CT})$ values for each gene were obtained by subtracting the mean threshold cycle (CT) of the reference GAPDH gene.

\section{PREPARATION OF PMNs}

Heparinized human blood was mixed with $1.5 \%$ dextran $/ 0.9 \%$ $\mathrm{NaCl}$ and allowed to settle undisturbed for $30 \mathrm{~min}$. The leukocyterich plasma was layered over a histopaque 1077 density gradient (Sigma) and centrifuged at $1300 \times \mathrm{g}$ for $30 \mathrm{~min}$. The cell pellet containing PMNs and erythrocytes was treated with hypotonic lysis buffer and washed with HBSS buffer without $\mathrm{Ca}^{2+} / \mathrm{Mg}^{2+}$. The preparation contained $\sim 95 \%$ neutrophils, as judged by morphological examination and cells were $>90 \%$ viable, as determined by Trypan blue dye exclusion. PMNs were washed $3 \times$ and re-suspended in HBSS buffer without $\mathrm{Ca}^{2+} / \mathrm{Mg}^{2+}$ at $1 \times 10^{7}$ cells/ml (Gibco). Prior to their use, calcein AM (1:1000, Becton Dickinson) was added to the suspension of PMN as described (Ruiz-Perez et al., 2011). The cells were incubated for $30 \mathrm{~min}$ at $37^{\circ} \mathrm{C}$, and washed up to $3 \times$ with PBS before being re-suspended in $1 \mathrm{ml}$ HBSS buffer without $\mathrm{Ca}^{2+} / \mathrm{Mg}^{2+}$.

\section{PMNs MIGRATION ASSAY}

Transmigration assays were performed according to previously described protocols (McCormick et al., 1993). Briefly, T84 cells were seeded on collagen-coated inverted inserts (diameter $12 \mathrm{~mm}$; pore size $3 \mu \mathrm{m}$ ) at a concentration of $\sim 7.5 \times 10^{5}$ cells per insert in $100 \mu \mathrm{l}$ of DMEM-F12 medium. The inserts were then placed in a 12-well plate and cultured until the monolayer were confluent (10-14 days). Prior to the infection, the cells were washed and incubated for $30 \mathrm{~min}$ a $37^{\circ} \mathrm{C}$ with DMEM-F12. The cells were infected on the apical surface with $\sim 1 \times 10^{6}$ of EHEC wild type strain 86-24 or its isogenic $l p f 1$ and $l p f 2$ single or $l p f 1$ lpf2 double mutants for $90 \mathrm{~min}$ at $37^{\circ} \mathrm{C}$ in $5 \% \mathrm{CO}_{2}$. Neutrophil chemoattractant formyl-Met-Leu-Phe (fMLP) $(0.2 \mu \mathrm{M}$, Sigma) was added as positive control. After infection, monolayers were washed $2 \times$ in HBSS and $20 \mu \mathrm{l}$ of solution containing $\sim 1 \times 10^{7} \mathrm{PMN} / \mathrm{ml}$ was added to the basolateral side. After $4 \mathrm{~h}$, neutrophils that migrated into the lower chamber were collected for quantification with a fluorometer. 


\section{STATISTICAL ANALYSIS}

Results from three independent experiments performed in triplicates were combined and analyzed by One-Way ANOVA with Dunnett posttest. A $P$-value of $<0.05$ was considering statistically significant.

\section{RESULTS}

\section{Lpf1 AND Lpf2 FIMBRIAE PARTICIPATE IN THE INDUCTION OF IL-8 SECRETED BY POLARIZED T84 CELLS}

We have previously demonstrated that Lpf fimbriae are involved in the adherence of EHEC to non-polarized intestinal epithelial T84 cells (Farfan et al., 2013). Using a polarized T84 cell model, a significant reduction in the number of adherent bacteria was observed on T84 cells infected with the lpfA1 (strain CVD468) and IpfA2 (strain AGT201) single mutants as compared to the wild-type strain. As previously observed with the non-polarized T84 cells, the number of adherent bacteria on polarized T84 cells infected by the lpfA1 lpfA2 double mutant (strain AGT210) was comparable to that in cells infected with the wild-type strain (Figure 1A).

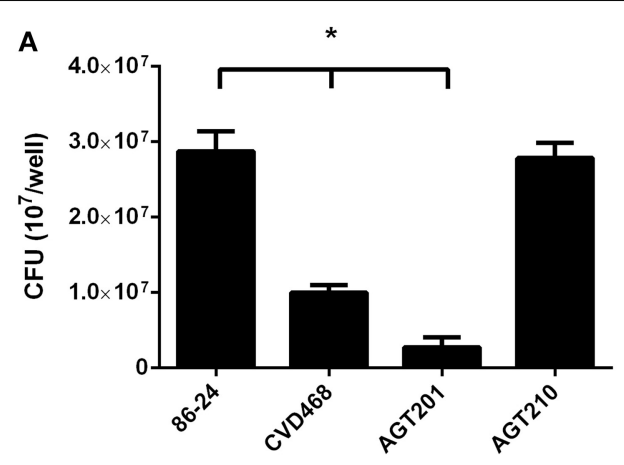

B

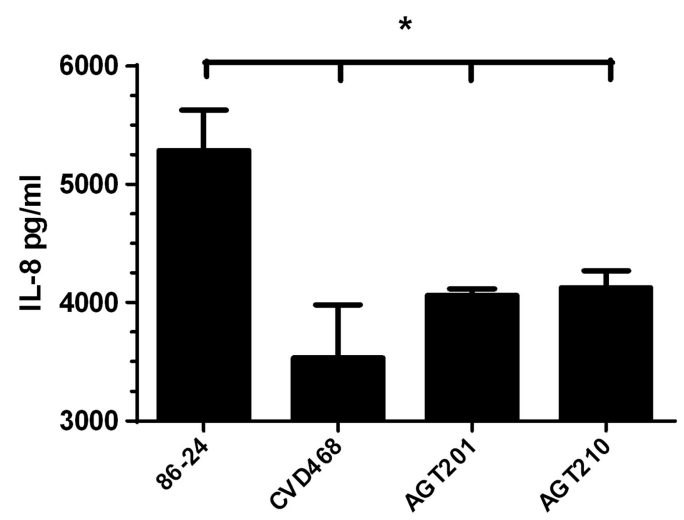

FIGURE 1 | Lpf fimbriae participate in the EHEC adherence and induction of IL-8 by polarized T84 cells. (A,B) Polarized T84 cells were infected with the EHEC wild-type strain 86-24 and isogenic mutants in IpfA1 (strain CVD468), IpfA2 (strain AGT201), and IpfA1 IpfA2 (strain AGT210). (A) After $3 \mathrm{~h}$ of infection the number of adherent bacteria was determined. (B) After $3 \mathrm{~h}$ of infection, infected cells were incubated with gentamicin for $3 \mathrm{~h}$ and the media from the basolateral side of the cells was collected and levels of secreted IL-8 were measured by ELISA. The bars represent the means of three experiments, with the error bars indicating one standard deviation. Asterisk represents statistical significance $(p<0.05)$.
Next, the participation of the Lpf fimbriae in the secretion of IL- 8 by polarized T84 cells was evaluated. Using cultured media from the basolateral compartment, it was found that the amount of IL- 8 secreted by cells infected with the lpfA1 and $l p f A 2$ single mutants, as well as lpfA1 lpfA2 double mutant, was significantly lower compared to that in cells infected with the wild-type strain (Figure 1B).

Complementarily, we infected polarized T84 cells with wildtype EHEC strain in the presence of serum raised against the Lpf1 fimbrial major A subunit (LpfA1 protein) or pre-bleed serum as a control. A significant reduction in the number of adherent bacteria (Figure 2A) and secreted IL-8 (Figure 2B) was observed when EHEC wild type strain was incubated with anti-Lpf1 serum.

In addition, we incubated T84 cells with fimbrial extracts obtained from the wild-type EHEC strain 86-24 and its isogenic lpf mutants. The induction of IL-8 secretion in cells incubated with fimbrial extracts obtained from the mutant strains was significantly lower compared to those from the wild-type strain

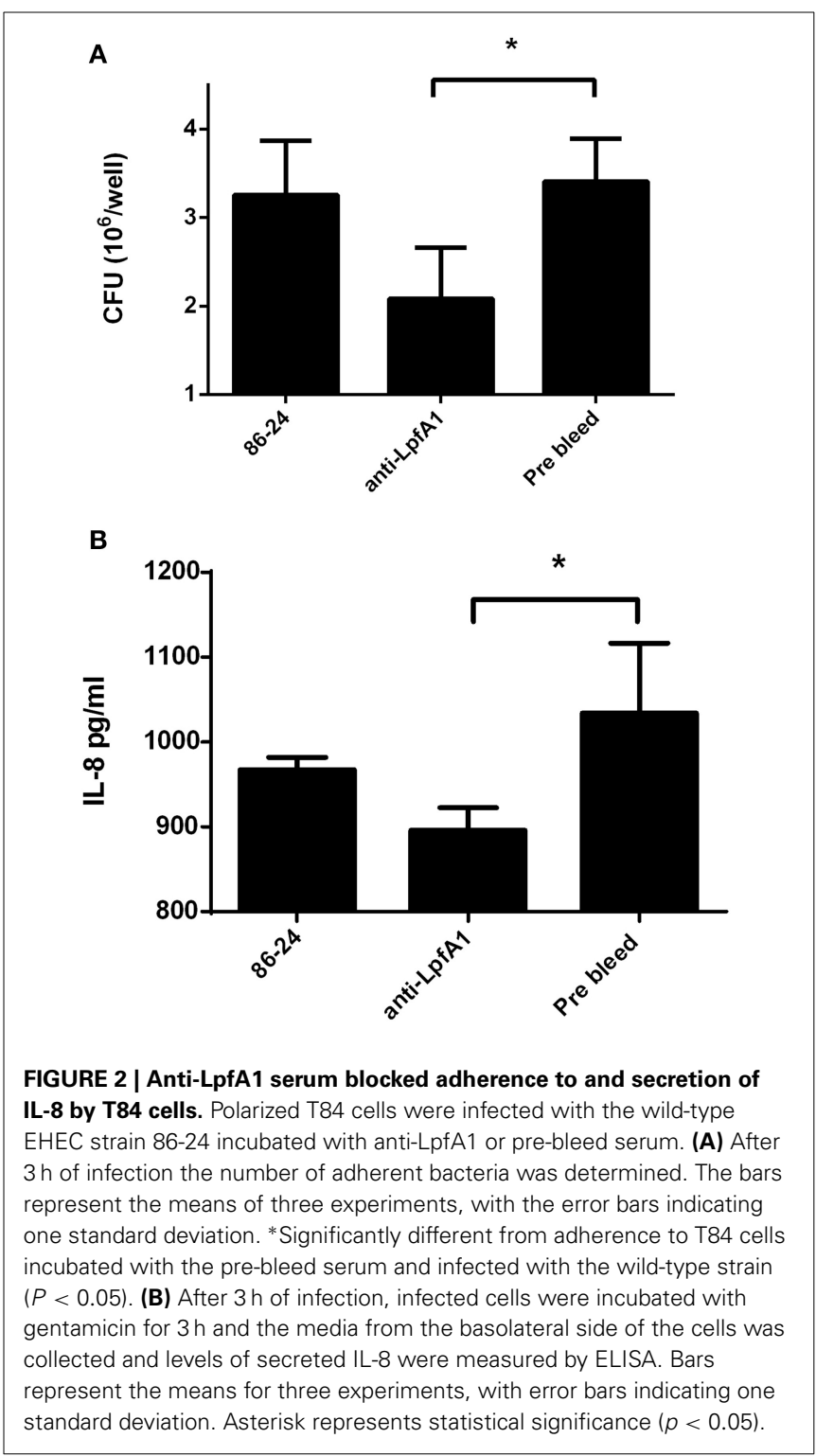


(Figure 3). Altogether, the data supported the participation of Lpf1 and Lpf2 fimbriae in the induction of the IL-8 secreted from intestinal epithelial cells.

\section{Lpf1 AND Lpf2 PARTICIPATE IN THE UP-REGULATION OF IL8, ICAM1 AND CCL2O GENES}

It has been previously proposed that Lpf fimbriae are involved in the expression of several pro-inflammatory genes, including IL-8, ICAM1, and CCL20 (Farfan et al., 2013). To determine the individual role of Lpf fimbriae in the expression of these genes, polarized T84 cells were infected with $l p f A 1$ and $l p f A 2$ single and double mutants. Real time PCR analyses indicated that Lpf1 and Lpf2 are equally involved in the expression of $I L-8$ gene $(\sim 8$ fold reduction compared to wild-type). In the case of ICAM1 and CCL20 genes, both fimbriae are also involved; however, a slight reduction in the expression of these genes was observed with polarized T84 cells infected with the lpfA2 mutant compared those infected with the $l p f A 1$ mutant (Figure 4).

\section{Lpf FIMBRIAE INVOLVEMENT IN PMN MIGRATION ACROSS T84 MONOLAYERS}

To characterize the role that Lpf fimbriae is playing in PMN transmigration, inverted polarized T84 cells were apically infected with wild-type EHEC strain, lpfA1 and $l p f A 2$ single and $l p f A 1$ lpfA2 double mutants. Subsequently, calcein-labeled PMNs were added to the basolateral surface and the PMNs that migrated to the apical compartment were detected. Compared to wild-type, a reduced migration of PMNs was observed in polarized T84 cells infected with the lpfA1 and the lpfA2 single as well as the lpfA1 lpfA2 double mutants. However, a significant difference was observed in the PMNs migration on cells infected with $l p f A 2$ single and $l p f A 1$ lpfA2 double mutants as compared to the $l p f A 1$ single mutant (Figure 5).

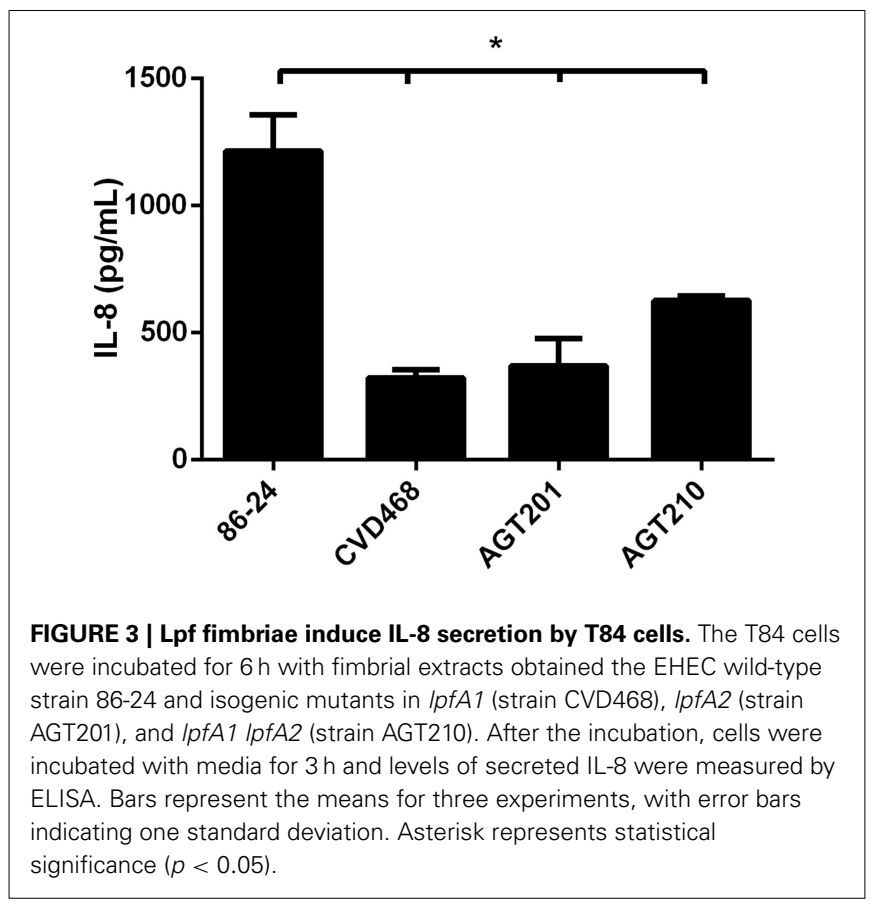

\section{DISCUSSION}

The inflammatory response induced by EHEC on intestinal cells involves the participation of multiple bacterial structures that interact with receptors at the cell surface and subsequent activation of intracellular signaling cascades. The NF- $\kappa$ B pathway is probably the most important signaling cascade involved in the inflammatory process induced by EHEC, as well as with other enteropathogens (Berin et al., 2002). Several EHEC virulence factors have been implicated in the activation of the NF- $\kappa$ B. The flagella was associated with the induction of high levels of IL-8 compared to Shiga toxin (Miyamoto et al., 2006). Shiga toxin

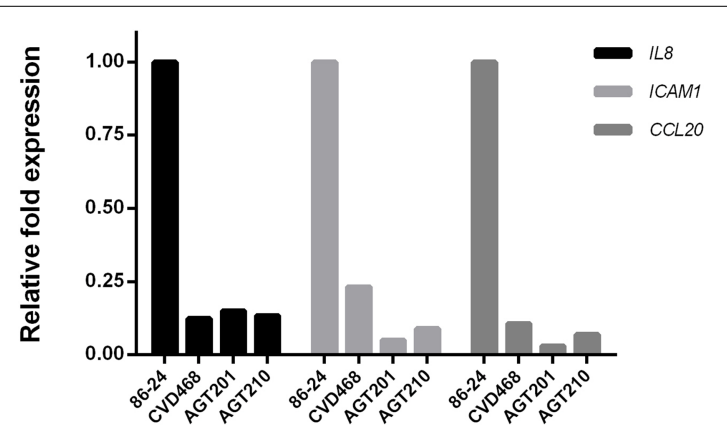

FIGURE 4 | Lpf fimbriae involvement in the expression of genes encoding inflammatory molecules. Polarized T84 cells were infected with the EHEC wild-type strain 86-24 and isogenic mutants in IpfA1 (strain CVD468), IpfA2 (strain AGT201), and IpfA1 IpfA2 (strain AGT210). After $3 \mathrm{~h}$ of infection, whole cell RNA was extracted to perform real-time RT-PCR analysis for IL8, ICAM1, and CCL20 genes. The fold variation of gene expression was obtained by the comparative cycle threshold $\left(\Delta \Delta C_{T}\right)$ method, normalized with GAPDH constitutive expression gene.

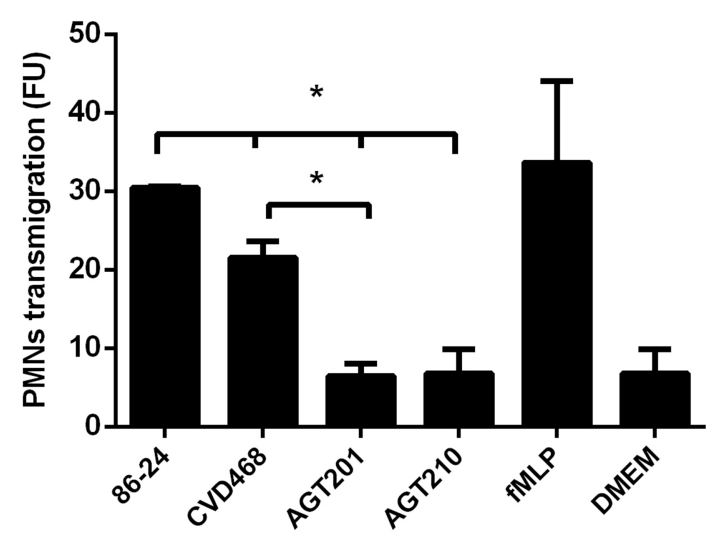

FIGURE 5 | Participation of Lpf fimbriae in the stimulation of PMN transepithelial migration. Inverted polarized T84 cells were infected with the EHEC wild-type strain 86-24 and isogenic mutants in IpfA1 (strain CVD468), IpfA2 (strain AGT201), and IpfA1 IpfA2 (strain AGT210). After infection, cells were incubated with $1 \times 10^{6}$ of calcein-AM labeled PMNs which were inoculated on the basolateral surface and penetration of cells through the membrane was measured fluorometrically after $4 \mathrm{~h}$. Bars represent the means for three experiments, with error bars indicating one standard deviation. Asterisk represents statistical significance $(p<0.05)$. FU, arbitrary fluorescent units. 
stimulates the secretion of IL-8, promoting a massive recruitment of leukocytes as result of the increase expression of adhesive molecules, such as E-selectin and ICAM-1 (Morigi et al., 1995). The Hemorrhagic coli pili (HCP) have been also shown to participate in the secretion of IL- 8 and TNF- $\alpha$ induced by EHEC infection of epithelial cells (Ledesma et al., 2010). Previously, we proposed that the Lpf fimbriae, a major adherence factor in EHEC, also participate in the inflammatory process (Farfan et al., 2013). Here, we provide supportive evidence associating the role of Lpf fimbriae in the EHEC-induced inflammation on intestinal epithelial cells.

In this study, we have shown that the two Lpf fimbriae described in EHEC O157:H7 contribute similarly to IL-8 secretion by polarized T84 cells, as described previously in a nonpolarized T84 cell model (Farfan et al., 2013). Using $l p f 1$ and $l p f 2$ single and $l p f 1$ lpf2 double mutants, we found that the secretion of IL- 8 by infected polarized T 84 cells was lower as compared to those infected with the wild-type strain (Figure 1B), Interestingly, there was no difference in the IL-8 levels found in supernatant of cells infected with the individual and double mutant strains, suggesting that both fimbriae contributed equally to the induction of IL-8 secretion. One plausible explanation of this phenotype might be the reduction of the number of adherent mutant bacteria attached to the surface of intestinal cells; however, the lpf1 lpf2 double mutant strain adheres at the same level observed with the wild type strain (Figure 1A), arguing against this possibility. A deeper analysis of the double mutant strain revealed that increase expression of curli at the surface of the bacteria is responsible for restoring the adherent phenotype to intestinal cells (Lloyd et al., 2012), but, in our model, not in the induction of IL-8 secreted. T84 cells infected with the $\operatorname{lpf1} \operatorname{lpf2} \operatorname{csg} A$ ( $\operatorname{csg} A$ gene encodes the major constituent of curli) triple mutant revealed that the amount of secreted IL- 8 is similar as compared to the lpf1 lpf2 double mutant (data not shown).

Additionally, infection of polarized T84 cells with the EHEC wild-type strain in presence of antiserum against the major subunit of the Lpfl fimbriae, LpfA1, showed a significant reduction in the adherence and the induction of IL-8 (Figures 2A,B). We performed similar experiments using an antiserum raised against LpfA2 major subunit of Lpf fimbria; however, no significant reduction in adherence of the EHEC strain 86-24 to intestinal cells was observed, probably due to either low specificity of this antiserum to recognize LpfA2 protein as determined by Western blot analysis (data not shown) or the recognition by the antibody of protein epitopes no associated with the adherence phenotype. To overcome this situation, we obtained fimbriae enriched-fractions from all the EHEC strains tested and when T84 cells were incubated with fimbrial fractions obtained from the mutant strains, less secreted IL- 8 was observed when compared to fimbrial extracts from the wild type strain (Figure 3). Our data supported the idea that both Lpf fimbriae participate in the stimulation of IL-8 secretion from intestinal epithelial cells, however, we cannot ruled out the contribution of these fimbriae in the stimulation of IL- 8 secretion dependent on the Lpf-mediated adhesion to cells.

Several signaling pathways regulate the expression of the inflammatory genes (Dahan et al., 2002). In a previous work, we described that several genes of the NF- $\mathrm{B}$ pathway (such as
IL8, ICAM1, and CCL20 genes) were down-regulated in T84 cells infected with the double mutant as compared to those infected with wild-type EHEC strain. However, these tests were performed using a PCR array (Farfan et al., 2013) and now we confirmed these observations in our polarized T84 cell model by quantification of the expression of these genes individually by real time PCR assay. Comparing the induction observed in cells infected with the wild-type strain, we found that the expression of IL8, ICAM1, and CCL20 genes were down-regulated in cells infected with all mutant strains tested (Figure 4). Surprisingly, the expression of ICAM1 and CCL20 genes in cells infected with the lpf2 mutant was lower compared to cells infected with $l_{p f 1}$ mutant.

The inflammation process on intestinal cells induced by enteric pathogens stimulates the activation and secretion of several markers that result in the recruitment of PMNs and their migration, getting access to the infection site and eventually eradicating the pathogen (McCormick et al., 1993). IL-8, ICAM-1, and CCL-20 play a pivotal role in the intestinal inflammation and the recruitment of PMNs during enteric infection. For EHEC, previous studies have found that the wild type EHEC strain 86-24 is able to induce the migration of PMNs, but paradoxically, this migration process increase the translocation of the Shiga toxin, favoring the access of the toxin to the bloodstream and distribution to target organs (Hurley et al., 2001). PMNs migration process is apparently not related to Shiga toxin, intimin, or other gene products encoded in the LEE PAI, suggesting the participation of other virulence factors in this process (Hurley et al., 2001).

Considering the role of Lpf on inflammation and that pathogenic $E$. coli adherence factors involved in inflammation, such as the aggregative adherence fimbriae (AAF) of enteroaggreggative E. coli, have also been implicated in the PMNs migration (Boll et al., 2012), we evaluate the role of both Lpf fimbriae in the PMNs migration trough polarized T84 cells. Our results showed that the translocation of PMNs was significantly lower in cells infected with $l p f 1$ and $l p f 2$ single and double mutant strains as compared to cells infected with the wild-type strain (Figure 5). We also found that infection with the single $l_{p f 2}$ and $l_{p f 1} l_{p f 2}$ double mutant, generated less PMN migration compared to single $l p f 1$ mutant, suggesting that Lpf2 fimbriae might have a more prominent role in the PMNs migration induced by EHEC. One possible explanation might be attributable to the differential gene expression of ICAM1 and CCL20 genes on polarized T84 cells infected with the $l p f 1$ and $l p f 2$ single mutants (Figure 4). Another possibility is the differential regulation controlling expression of these fimbrial structures. For Lpf1, it is known that the histonelike nucleoid protein (H-NS) binds to the regulatory sequence of the E. coli O157:H7 lpf1 operon and "silences" its transcription, while Ler inhibits the action of the H-NS leading to expression of the lpf1 operon (Torres et al., 2007; Rojas-López et al., 2011). For the $l p f 2$ operon, it has been recently demonstrated that bile salts, iron and the Fur protein participate in its expression (ArenasHernández et al., 2014). It would be interesting to evaluate in the future protein expression of both Lpf fimbriae using different environmental conditions applied in our polarized cell infection model.

In conclusion, this report provides new evidence supporting the role of Lpf fimbriae in the induction of host pro-inflammatory 
responses to EHEC infection. Along with their well-studied function as adherence factors, Lpf fimbriae are multifunctional virulence appendages that might be considered in the design of new strategies to control the infection by this pathogen.

\section{ACKNOWLEDGMENTS}

This work was supported by grant FONDECYT 1120809 to Mauricio J. Farfan, FONDECYT 1110260 to Roberto M. Vidal and Mauricio J. Farfan, and NIH/NIAID AI079154 to Alfredo G. Torres. The contents are solely the responsibility of the authors and do not necessarily represent the official views of the NIAID or NIH.

\section{REFERENCES}

Arenas-Hernández, M. M. P., Rojas-López, M., Medrano-López, A., Nuñez-Reza, K. J., Puente, J. L., Martínez-Laguna, Y., et al. (2014). Environmental regulation of the long polar fimbriae 2 of enterohemorrhagic Escherichia coli O157:H7. FEMS Microbiol. Lett. 357, 105-114. doi: 10.1111/1574-6968.12513

Berin, M. C., Darfeuille-Michaud, A., Egan, L. J., Miyamoto, Y., and Kagnoff, M. F. (2002). Role of EHEC O157:H7 virulence factors in the activation of intestinal epithelial cell NF-kappaB and MAP kinase pathways and the upregulated expression of interleukin 8. Cell. Microbiol. 4, 635-648. doi: 10.1046/j.14625822.2002.00218.x

Boll, E. J., Struve, C., Sander, A., Demma, Z., Nataro, J. P., McCormick, B. A., et al. (2012). The fimbriae of enteroaggregative Escherichia coli induce epithelial inflammation in vitro and in a human intestinal xenograft model. J. Infect. Dis. 206, 714-722. doi: 10.1093/infdis/jis417

Coburn, B., Li, Y., Owen, D., Vallance, B. A., and Finlay, B. B. (2005). Salmonella enterica serovar Typhimurium pathogenicity island 2 is necessary for complete virulence in a mouse model of infectious enterocolitis. Infect. Immun. 73, 3219-3227. doi: 10.1128/IAI.73.6.3219-3227.2005

Dahan, S., Busuttil, V., Imbert, V., Peyron, J.-F., Rampal, P., and Czerucka, D. (2002). Enterohemorrhagic Escherichia coli infection induces interleukin-8 production via activation of mitogen-activated protein kinases and the transcription factors NF-kappaB and AP-1 in T84 cells. Infect. Immun. 70, 2304-2310. doi: 10.1128/IAI.70.5.2304-2310.2002

Farfan, M. J., Cantero, L., Vergara, A., Vidal, R., and Torres, A. G. (2013). The long polar fimbriae of STEC O157:H7 induce expression of pro-inflammatory markers by intestinal epithelial cells. Vet. Immunol. Immunopathol. 152, 126-131. doi: 10.1016/j.vetimm.2012.09.017

Farfan, M. J., and Torres, A. G. (2012). Molecular mechanisms that mediate colonization of Shiga toxin-producing Escherichia coli strains. Infect. Immun. 80, 903-913. doi: 10.1128/IAI.05907-11

Gobert, A. P., Vareille, M., Glasser, A.-L., Hindré, T., de Sablet, T., and Martin, C. (2007). Shiga toxin produced by enterohemorrhagic Escherichia coli inhibits PI3K/NF-kappaB signaling pathway in globotriaosylceramide-3negative human intestinal epithelial cells. J. Immunol. 178, 8168-8174. doi: 10.4049/jimmunol.178.12.8168

Harrington, S. M., Strauman, M. C., Abe, C. M., and Nataro, J. P. (2005). Aggregative adherence fimbriae contribute to the inflammatory response of epithelial cells infected with enteroaggregative Escherichia coli. Cell. Microbiol. 7, 1565-1578. doi: 10.1111/j.1462-5822.2005.00588.x

Hurley, B. P., Thorpe, C. M., and Acheson, D. W. (2001). Shiga toxin translocation across intestinal epithelial cells is enhanced by neutrophil transmigration. Infect. Immun. 69, 6148-6155. doi: 10.1128/IAI.69.10.61486155.2001

Izquierdo, M., Navarro-Garcia, F., Nava-Acosta, R., Nataro, J. P., Ruiz-Perez, F., and Farfan, M. J. (2014). Identification of cell surface-exposed proteins involved in the fimbria-mediated adherence of enteroaggregative Escherichia coli to intestinal cells. Infect. Immun. 82, 1719-1724. doi: 10.1128/IAI.01 651-13

Ledesma, M. A., Ochoa, S. A., Cruz, A., Rocha-Ramírez, L. M., Mas-Oliva, J., Eslava, C. A., et al. (2010). The hemorrhagic coli pilus (HCP) of Escherichia coli $\mathrm{O} 157: \mathrm{H} 7$ is an inducer of proinflammatory cytokine secretion in intestinal epithelial cells. PLoS ONE 5:e12127. doi: 10.1371/journal.pone.0012127
Lloyd, S. J., Ritchie, J. M., and Torres, A. G. (2012). Fimbriation and curliation in Escherichia coli O157:H7: a paradigm of intestinal and environmental colonization. Gut Microbes 3, 272-276. doi: 10.4161/gmic.20661

McCormick, B. A., Colgan, S. P., Delp-Archer, C., Miller, S. I., and Madara, J. L. (1993). Salmonella typhimurium attachment to human intestinal epithelial monolayers: transcellular signalling to subepithelial neutrophils. J. Cell Biol. 123, 895-907. doi: 10.1083/jcb.123.4.895

Miyamoto, Y., Iimura, M., Kaper, J. B., Torres, A. G., and Kagnoff, M. F. (2006). Role of Shiga toxin versus H7 flagellin in enterohaemorrhagic Escherichia coli signalling of human colon epithelium in vivo. Cell. Microbiol. 8, 869-879. doi: 10.1111/j.1462-5822.2005.00673.x

Morigi, M., Micheletti, G., Figliuzzi, M., Imberti, B., Karmali, M. A., Remuzzi, A., et al. (1995). Verotoxin-1 promotes leukocyte adhesion to cultured endothelial cells under physiologic flow conditions. Blood 86, 4553-4558.

Paulukat, J., Bosmann, M., Nold, M., Garkisch, S., Kämpfer, H., Frank, S., et al. (2001). Expression and release of IL-18 binding protein in response to IFNgamma. J. Immunol. 167, 7038-7043. doi: 10.4049/jimmunol.167.12.7038

Pennington, H. (2010). Escherichia coli O157. Lancet 376, 1428-1435. doi: 10.1016/S0140-6736(10)60963-4

Rojas-López, M., Arenas-Hernández, M. M. P., Medrano-López, A., Martínez de la Peña, C. F., Puente, J. L., Martínez-Laguna, Y., et al. (2011). Regulatory control of the Escherichia coli O157:H7 lpf1 operon by H-NS and Ler. J. Bacteriol. 193, 1622-1632. doi: 10.1128/JB.01082-10

Ruiz-Perez, F., Wahid, R., Faherty, C. S., Kolappaswamy, K., Rodriguez, L., Santiago, A., et al. (2011). Serine protease autotransporters from Shigella flexneri and pathogenic Escherichia coli target a broad range of leukocyte glycoproteins. Proc. Natl. Acad. Sci. U.S.A. 108, 12881-12886. doi: 10.1073/pnas.11010 06108

Sawa, Y., Ueki, T., Hata, M., Iwasawa, K., Tsuruga, E., Kojima, H., et al. (2008). LPS-induced IL-6, IL-8, VCAM-1, and ICAM-1 expression in human lymphatic endothelium. J. Histochem. Cytochem. 56, 97-109. doi: 10.1369/jhc.7A7299.2007

Szabady, R. L., and McCormick, B. A. (2013). Control of neutrophil inflammation at mucosal surfaces by secreted epithelial products. Front. Immunol. 4:220. doi: 10.3389/fimmu.2013.00220

Torres, A. G., Giron, J. A., Perna, N. T., Burland, V., Blattner, F. R., AvelinoFlores, F., et al. (2002). Identification and characterization of $l p f A B C C^{\prime} D E$, a fimbrial operon of enterohemorrhagic Escherichia coli O157:H7. Infect. Immun. 70, 5416-5427. doi: 10.1128/IAI.70.10.5416-5427.2002

Torres, A. G., Kanack, K. J., Tutt, C. B., Popov, V., and Kaper, J. B. (2004). Characterization of the second long polar (LP) fimbriae of Escherichia coli O157:H7 and distribution of LP fimbriae in other pathogenic E. coli strains. FEMS Microbiol. Lett. 238, 333-344. doi: 10.1016/j.femsle.2004. 07.053

Torres, A. G., López-Sánchez, G. N., Milflores-Flores, L., Patel, S. D., Rojas-López, M., Martínez de la Peña, C. F., et al. (2007). Ler and H-NS, regulators controlling expression of the long polar fimbriae of Escherichia coli O157:H7. J. Bacteriol. 189, 5916-5928. doi: 10.4161/gmic.20661

Conflict of Interest Statement: The authors declare that the research was conducted in the absence of any commercial or financial relationships that could be construed as a potential conflict of interest.

Received: 17 October 2014; accepted: 11 December 2014; published online: 08 January 2015.

Citation: Vergara AF, Vidal RM, Torres AG and Farfan MJ (2015) Long polar fimbriae participates in the induction of neutrophils transepithelial migration across intestinal cells infected with enterohemorrhagic E. coli O157:H7. Front. Cell. Infect. Microbiol. 4:185. doi: 10.3389/fcimb.2014.00185

This article was submitted to the journal Frontiers in Cellular and Infection Microbiology.

Copyright (๑) 2015 Vergara, Vidal, Torres and Farfan. This is an open-access article distributed under the terms of the Creative Commons Attribution License (CC BY). The use, distribution or reproduction in other forums is permitted, provided the original author(s) or licensor are credited and that the original publication in this journal is cited, in accordance with accepted academic practice. No use, distribution or reproduction is permitted which does not comply with these terms. 